\title{
LEARNING ELECTRIC CIRCUITS: THE CONTENT OF ELEMENTARY SCHOOL STUDENTS' WRITTEN ARGUMENTS
}

Constantinia Balia, Michael Skoumios ${ }^{i}$ University of the Aegean, Rhodes, Greece

\begin{abstract}
:
This study aimed to investigate the impact of a teaching intervention for electric circuits on the content of elementary school students' written arguments. Educational material was constructed based on the constructivist approach to learning with the use of science and engineering practices and was implemented with 34 students aged 11 years. A questionnaire that was provided to students before and after the teaching intervention (pre-test, post-test) was used to collect the data. Data analysis was carried out by classifying the sufficiency of the components of the arguments into levels. The analysis of written answers (arguments) was performed with a framework for assessing the content of arguments (appropriateness of their components: claim, evidence, and reasoning). The data analysis showed that the students significantly improved the content of their arguments.
\end{abstract}

Keywords: content of written arguments, science and engineering practices, learning electric circuits, elementary school

\section{Introduction}

In the new framework for science education of the US National Research Council, the need to involve students in argument from evidence is highlighted (NRC, 2012). Although the construction of arguments by the students has been recognized as important, the research that has been conducted on the quality of students' written arguments is limited (McNeill \& Krajcik, 2007; Sampson \& Walker, 2012; Songer \& Gotwals, 2012). In addition, there are no research papers investigating the quality of students' arguments on electric circuits. This paper focuses on the study of the contribution of a teaching intervention for electrical circuits to the content of elementary school students' arguments.

\footnotetext{
i Correspondence: email skoumios@rhodes.aegean.gr, skoumios@otenet.gr
} 


\section{Theoretical Framework}

\subsection{Teaching Science Through Practices}

Research data shows that students enter the learning process already possessing several alternative conceptions about the world they live in (Driver et al., 1985). It was found that in most cases, students' initial conceptions differ from school version of science knowledge. According to the constructivist approach to learning, students are not passive recipients of knowledge, but they actively construct knowledge through an interactive process between their initial conceptions and the conceptions they receive from their educational environment (Glasersfeld, 1995).

The intellectual work related to elaborating and changing conceptions is based on students' engagement in science and engineering practices (Cherbow et al., 2020; NGSS Lead States, 2013). Practices are defined "as meaningful practices in which learners are engaged in building, refining, and applying scientific knowledge, to understand the world" (NRC, 2012, p. 254). Engaging in argument from evidence is one of the eight science and engineering practices. The main aspect of this practice is the production of arguments by the students.

\subsection{Students' Arguments}

Arguments, according to Toulmin (1958), incorporate claims, data (supporting the claims), warrants (proving why the data supports the claims), backings (information that strengthen the warrants, qualifiers (that represent the confidence that is warranted by the argument), and rebuttals (indicating the conditions under which the data together with the warrants do not lead to claims). A modified type of this model has been proposed by McNeill and Krajcik (2012). In particular, an argument has four components: claim, evidence, reasoning and rebuttal. The claim makes an assertion that addresses the question that the students are trying to answer. The evidence is scientific data that supports the claim. The reasoning is the justification for why their data counts as evidence to support their claim which often requires the use of scientific principles. The rebuttal explains how or why an alternative claim is wrong.

The criteria for the quality of an argument are the structure and the content of the argument. The structure of an argument is related to the presence and the sufficiency of its components and the content of an argument is related to the appropriateness of its components when the latter are evaluated with regard to school science knowledge (Sandoval \& Millwood, 2005). In particular, an argument is considered appropriate when it includes a claim (which consistent with school science knowledge), evidence (supporting the specific claim according to school science knowledge), and reasoning linking the evidence to the claim through scientific principles and a rebuttal including another claim that is supported by evidence and reasoning according to school science knowledge. 


\section{Literature Review}

Research has been carried out thoroughly investigating students' conceptions about electric circuits (Glauert, Esme, \& Bridget, 2009; Shipstone, 1988). It has found that students have conceptions that are different from the school science knowledge for electric circuits. Furthermore, research studying the impact of teaching interventions for electric circuits has been conducted and the results of these studies showed that some students during the teaching interventions constructed conceptions about the electrical circuits in the direction of school science knowledge (Afra et al., 2009; Chiu \& Lin, 2005). Regarding the construction of arguments, it turned out that students suggest claims without justifying them (Jiménez-Aleixandre et al., 2000; Sadler, 2004) or propose evidence insufficient and inappropriate for justifying the claims (Jiménez-Aleixandre et al., 2000; McNeill \& Krajcik, 2012). Furthermore, students rarely use reasoning in the arguments they construct (Mastrogiorgaki \& Skoumios, 2018; McNeill \& Krajcik, 2012; Songer \& Gotwals, 2012).

Although students' conceptions about electric circuits have been investigated and research studying the impact of teaching interventions on students' conceptions has been conducted, there are no research papers studying the impact of teaching interventions to the content of students' arguments for electric circuits.

\section{Purpose and Research Questions}

The purpose of this study is to investigate the impact of a teaching intervention for electric circuits, which is based on the constructivist approach to learning with the use of science and engineering practices, on the content of written arguments of elementary school students (11 years old).

In particular, the present paper aims to answer the following research questions:

a) What is the impact of the proposed teaching intervention on the appropriateness of the claims of elementary school students' written arguments?

b) What is the impact of the proposed teaching intervention on the appropriateness of the evidence of elementary school students' written arguments?

c) What is the impact of the proposed teaching intervention on the appropriateness of the reasoning of elementary school students' written arguments?

\section{Methodology}

\subsection{Research Process Phases and Participants}

A single group pre-test and post-test quasi-experimental design was adopted. The research processes included two stages. In the first stage, the educational material, and a questionnaire, both related to electric circuits, were developed. In the second stage, the educational material was implemented in the students and the questionnaire was completed before and after the teaching intervention (pre-test, post-test). The educational 
material was implemented in elementary schools for a period of six weeks, including a total of 18 hours.

The research was carried out with the participation of 34 elementary school students of Greece, aged 11 years (18 boys and 16 girls). All the students could speak and write in Greek, while before the teaching intervention, the students had never been taught electric circuits.

\subsection{Educational Material and Teaching Intervention}

The educational material about electric circuits was constructed based on the constructivist view of learning with the use of science and engineering practices. It covered five units: electric circuit, electric current, conductors and insulators, connecting lamps in series, connecting lamps in parallel.

The construction of each unit used the learning model 5E by Bybee et al. (2006), which incorporates five phases: engagement, exploration, explanation, elaboration, and evaluation.

\section{a. Engagement}

In the engagement phase, the students engaged in activities that pointed to highlight their initial conceptions and help them realize the disagreements they had with each other. Through group discussions, students asked the questions they were going to investigate.

\section{b. Exploration}

In the exploration phase, the students became familiar with the processes of planning and carrying out investigations: they asked research questions and made research presumptions, they controlled variables (independent variable, dependent variable, control variables), they reported and implemented labwork processes.

\section{c. Explanation}

In the explanation phase, the students processed the data and acknowledged tendencies within the data. It was planned that the students would construct arguments (based on the evidence collected from the labwork). The components of an argument (claim, evidence, reasoning) are presented and explained to the students by the teacher. Moreover, the necessity of constructing arguments was discussed, and the students constructed and evaluated arguments (with the help of self-evaluation sheets and under the guidance of the teacher). The components of the arguments that were presented to the students did not include rebuttal because rebuttal is suggested for secondary education students, after the latter have become familiar with the other three components (claim, evidence, reasoning) (Berland \& McNeill, 2010).

\section{d. Elaboration}

In the elaboration phase, the students handled problems different from those they had initially worked out so that they could examine the extent to which they systematically activate new knowledge in case of new problems. The students became familiar with activities carried out for identifying the components of the argument, and they constructed and evaluated arguments. 


\section{e. Evaluation}

In the evaluation phase, the students compared the new knowledge (that they constructed) with their initial conceptions to improve self-control and register their cognitive progress.

\subsection{Data Collection and Analysis}

Data collection used written questionnaire. A small number of students (three 11-yearold students), two elementary education teachers and two science education researchers were provided with the initial version of the questionnaire so that the internal validity of the questionnaire could be ensured. The comments of the above were taken into account in the final form of the questionnaire, which included five problems that asked from students' predictions and justifications for issues related to electric circuits (method of connecting the battery with the lamp in a simple electric circuit, conservation of electric current, conductivity of materials, illumination of lamps connected in series, illumination of lamps connected in parallel). Every problem included one question and data related to the question. The students were asked to answer the question and justify their answers. The Appendix includes a problem about the illumination of lamps connected in parallel. The written arguments produced by the students in their attempt to answer the questions that were included in the pre-test and the post-test constituted the research data. They were allotted one hour to complete each of the questionnaires. A total of 170 written arguments were collected from pre-test and 170 written arguments from post-test.

The evaluation of the content of students' arguments required the appropriateness of the components of students' arguments (claim, evidence, reasoning), when the latter are evaluated regarding school science knowledge. Each component of an argument was classified into one of the two levels (Level 1 and Level 2). A component of an argument (claim, evidence, reasoning) is classified into Level 1 as long as it is absent or inappropriate, while it is classified into Level 2 as long as it is appropriate. It should be noted that the evaluation of arguments was restricted to three out of the four components of the arguments, i.e. the claim, the evidence and the reasoning.

Two arguments used by the students are set out below concerning the question included in the Appendix, accompanied by their evaluations of their contents.

\section{Argument 1: "Maybe, their illumination is affected because the current is shared."}

Evaluation of argument 1: As for its content, it includes a claim ("Maybe, their illumination is affected") and a piece of evidence ("the current is shared"). More specifically, a claim considered inappropriate is included (Level 1), inappropriate evidence is included (Level 1), while no reasoning is included (Level 1).

Argument 2: "Their illumination is not affected. When there are two lamps, they provide the same light, and if there are three lamps, they also provide the same light."

Evaluation of argument 2: As for the content of the argument, it includes a claim ("Their illumination is not affected"), evidence ("When there are two lamps, they provide the same light, 
and if there are three lamps, they also provide the same light".) More specifically, a claim considered appropriate is included (Level 2), considered appropriate is included (Level 2), while no reasoning is included (Level 1).

Students' arguments were evaluated by two researchers that worked independently. Their differences were settled through discussions.

The next step after the arguments were analyzed was to create tables presenting the frequencies and the percentages of the levels that refer to the appropriateness of the components of students' arguments in questionnaires that was handed to the students both before and after the teaching intervention (pre-test, post-test). McNemar's test was used for contrasting the levels (Level 1, Level 2) of the components of students' arguments in the pre-test and the post-test.

\section{Results}

Table 1 presents the frequencies and the percentages of the levels referring to the appropriateness of claims, evidence and reasoning of students' written arguments in the pre-test and the post-test.

Table 1: Appropriateness levels of claims, evidence and reasoning of students' written arguments before and after the teaching interventions: frequencies and percentages

\begin{tabular}{|c|c|c|c|c|c|c|c|c|c|c|c|c|}
\hline \multirow[t]{3}{*}{ Levels } & \multicolumn{4}{|c|}{ Claim } & \multicolumn{4}{|c|}{ Evidence } & \multicolumn{4}{|c|}{ Reasoning } \\
\hline & \multicolumn{2}{|c|}{ Pre-test } & \multicolumn{2}{|c|}{ Post-test } & \multicolumn{2}{|c|}{ Pre-test } & \multicolumn{2}{|c|}{ Post-test } & \multicolumn{2}{|c|}{ Pre-test } & \multicolumn{2}{|c|}{ Post-test } \\
\hline & $\mathrm{f}$ & $\%$ & $\mathrm{f}$ & $\%$ & $\mathrm{f}$ & $\%$ & $\mathrm{f}$ & $\%$ & $\mathrm{f}$ & $\%$ & $\mathrm{f}$ & $\%$ \\
\hline 1 & 165 & 97.1 & 70 & 41.2 & 170 & 100 & 120 & 70.6 & 170 & 100 & 135 & 79.4 \\
\hline 2 & 5 & 2.9 & 100 & 58.8 & 0 & 0 & 50 & 29.4 & 0 & 0 & 35 & 20.6 \\
\hline
\end{tabular}

With regard to the appropriateness of the claims included in students' arguments in the pre-test and the post-test, it emerged that, while in the pre-test most claims were classified into Level 1 (97.1\%), in post-test most claims were classified into Level 2 (58.8\%).

As for the appropriateness of the evidence included in students' arguments, it was found that although in the pre-test all the evidence was classified into Level $1(100 \%)$, in the post-test the percentage of evidence classified into Level 1 decreased $(70.6 \%)$, while the percentage of Level 2 increased (29.4\%).

As regards the appropriateness of the reasoning included in students' arguments in the pre-test and the post-test, it was found that although in the pre-test all the reasoning was classified into Level $1(100 \%)$, in the post-test, despite the high percentage classified in Level 1 (79.4\%), the percentage classified into Level 2 increased $(20.6 \%)$.

Furthermore, McNemar's test shows that there is a statistically significant correlation between the appropriateness levels of students' claims $\left[\chi^{2}(1)=17.0530\right.$, $p=0.0001]$, evidence $\left[\chi^{2}(1)=8.1000, p=0.0044\right]$ and reasoning $\left[\chi^{2}(1)=5.1430, p=0.0233\right]$ in the pre-test and the post-test. As a result, a significant improvement was found in the appropriateness of students' claims, evidence and reasoning from the pre-test to the posttest. 


\section{Discussions and Conclusion}

It was found that the students, before the teaching intervention (as shown by the pretest), produced mainly inappropriate arguments with respect to their content. Most of the students did not suggest appropriate claims, evidence and reasoning.

The above results are in line with the results of other studies, which have shown that students enter the educational process already possessing a number of formed conceptions about the world they live and these conceptions differ from scientific knowledge (Driver et al., 1985). Moreover, the above results are in line with the results of other studies, which have shown that the quality of the arguments produced by students of different age is low (McNeill \& Krajcik, 2007, 2012; Songer \& Gotwals, 2012). During science teaching the students are usually not taught the components of an argument and rarely are they asked to write and evaluate arguments (Driver et al., 2000).

After the implementation of the teaching intervention (as it resulted from the posttest), it was found that the content of students' written arguments was improved. In particular, the students improved their ability to develop appropriate claims, appropriate evidence supporting the claims, and develop appropriate reasoning, through which they linked the evidence with the claims.

The improvement in the content of students' written arguments could be attributed to the educational material used. Through the activities of the educational material, students had the opportunity to become familiarized with the components of an argument (claim, evidence, reasoning), the way these components are connected with each other as well as the way the students can evaluate an argument. These processes can contribute to improving the quality of arguments (Chen et al., 2016; McNeill \& Krajcik, 2012). Furthermore, the activities which allowed the students working in groups to express and elaborate on their conceptions, created the necessary conditions for a discussion among the students. The discussion among the students, in which the students were trying to support their claims and convince their peers through evidence and reasoning, helped the students to actively engage into dialogic argumentation and to improve the quality of students' written arguments (González-Howard \& McNeill, 2019). The results of the present research are subject to the restrictions of a small sample, which may not be considered representative of the total population of students. An additional restriction is the use of the questionnaire as the only data collection tool.

The present study was exclusively focused on studying the content of students' written arguments without examining their structure. Further research is required, which will study the progress on the structure of students' arguments and will contrast it with the progress on their content. Moreover, the present study was focused on investigating written arguments. It would be interesting to investigate the progress on students' oral arguments and contrast them with their written arguments. Also, this paper was centered on investigating students' arguments before and after the teaching intervention. It is suggested that the quality of students' arguments be studied during teaching so that students' progression can be investigated. 


\begin{abstract}
About the Author(s)
Constantinia Balia: Elementary school teacher Constantinia Balia obtained a first degree in education from the University of Thessaly in 2004, a second degree in chemistry from the Aristotle University of Thessaloniki in 2014 and a master's degree in education from the Hellenic Open University in 2019. His research interests include teaching science in elementary school. He is currently teaching in an elementary school in Greece.

Michael Skoumios: Associate Professor Michael Skoumios obtained a first degree in physics from the National and Kapodistrian University of Athens in 1987, a second degree in education from the University of Aegean in 1992, and his $\mathrm{PhD}$ in science education from the Hellenic Open University in 2005. His research interests include science concept learning and teaching science in elementary and secondary schools. He is currently teaching science education in the Department of Primary Education of the University of the Aegean.
\end{abstract}




\section{Appendix}

\section{A Question that is included in Pre-test and Post-test}

Mrs. Ioanna asked Pigi with her fellow students to study whether the number of lamps connected in parallel in a circuit affects their illumination. They make the following electric circuits with the same batteries and the same lamps.

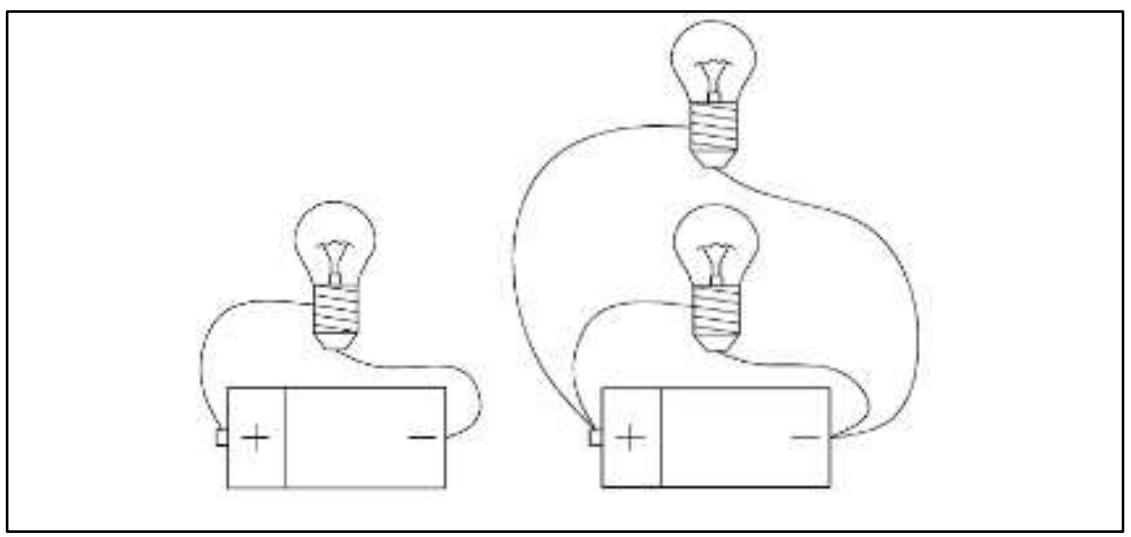

They notice that the illumination of the lamps in the second circuit is the same. They connect three lamps in parallel and notice that the lamps of the third circuit illuminate the same as the other two circuits.

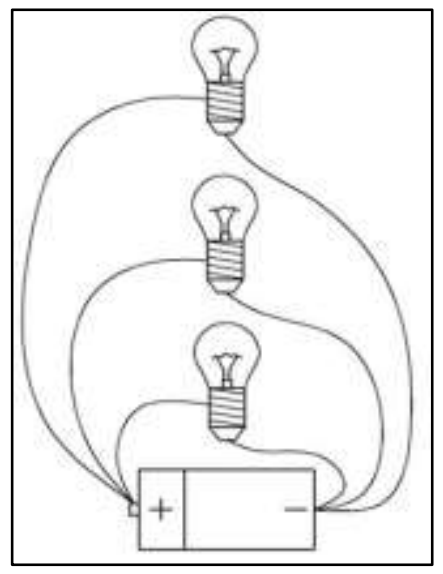

Pigi and her fellow students need your help. Use the above information to write and justify your answer to the following question of Pigi:

Does the number of lamps connected in parallel in a circuit affect their illumination? While writing your answer to Pigi, do not forget to justify it as thoroughly as you can. 


\section{References}

Afra, N. C., Osta, I., \& Zoubeir W. (2009). Students alternative conceptions about electricity and effect of inquiry-based teaching strategies. International Journal of Science and Mathematics Education, 7(1), 103-132.

Berland, L., \& McNeill, K. (2010). A Learning Progression for Scientific Argumentation: Understanding Student Work and Designing Supportive Instructional Contexts. Science Education, 94, 765-793.

Bybee, R. W., Taylor, J. A., Gardner, A., Van Scotter, P., Powell, J. C., Westbrook, A., \& Landes, N. (2006). The BSCS 5E instructional model: Origins and effectiveness. Colorado Springs.

Chen, H.-T., Wang, H.-H., Lu, Y.-Y., Lin, H., \& Hong, Z.-R. (2016). Using a modified argument-driven inquiry to promote elementary school students' engagement in learning science and argumentation. International Journal of Science Education, 38(2), 170-191.

Cherbow, K., McKinley, M., McNeill, K. \& Lowenhaupt, R. (2020). An analysis of science instruction for the science practices: Examining coherence across system levels and components in current systems of science education in K-8 schools. Science Education, 104(3), 446-478.

Chiu, M. H., \& Lin, J. W. (2005). Promoting Fourth Graders' Conceptual Change of Their Understanding of Electric Current via Multiple Analogies. Journal of Research in Science Teaching, 4 (4), 429- 464.

Driver, R., Guesne, E., \& Tiberghien, A. (Ed.). (1985). Children's Ideas in Science. Milton Keynes [Buckinghamshire]; Philadelphia: Open University Press.

Driver, R., Newton, P., \& Osborne, J. (2000). Establishing the norms of scientific argumentation in classrooms. Science Education, 84(3), 287-312.

Glasersfeld von, E. (1995). Radical constructivism: a way of knowing and learning. Falmer Press.

Glauert, \& Esme Bridget (2009). How Children Understand Electric Circuits: Prediction, explanation and exploration. International Journal of Science Education, 31(8), 1025 1047.

González-Howard, M., \& McNeill, K. L. (2019). Supporting linguistically diverse students in scientific argumentation across writing and talking. In Spycher, P. \& Haynes, E. (Eds.). Culturally and linguistically diverse learners and STEAM: Teachers and researchers working in partnership to build a better path forward (pp. 77-94). Charlotte, NC: Information Age Publishing.

Jiménez-Aleixandre, M. P., Bugallo Rodríguez, A., \& Duschl, R. A. (2000). “Doing the lesson" or "Doing Science": argument in high school genetics. Science Education, $84(6), 757-792$.

Mastrogiorgaki, M. \& Skoumios, M. (2018). Improving the Structure of Students' Arguments Through a Teaching-Learning Sequence on Newton's Second Law. European Journal of Education Studies, 5(5), 1-10. 
McNeill K. L., \& Krajcik J. (2007). Middle school students' use of appropriate and inappropriate evidence in writing scientific explanations. In M. Lovett \& P. Shah (Eds.), Thinking with Data: The proceedings of the 33rd Carnegie Symposium on Cognition (pp. 233-265). Lawrence Erlbaum Associates, Inc.

McNeill, K. L., \& Krajcik, J. (2012). Supporting grade 5-8 students in constructing explanations in science: The claim, evidence and reasoning framework for talk and writing. New York. NY: Pearson Allyn \& Bacon.

National Research Council (NRC). (2012). A Framework for K-12 Science Education: Practices, crosscutting concepts, and core ideas. Washington, DC: National Academies Press.

NGSS Lead States. (2013). Next Generation Science Standards: For States, By States. Washington, DC: The National Academies Press.

Sadler, T. D. (2004). Informal reasoning regarding socioscientific issues: A critical review of research. Journal of Research in Science Teaching, 41(5), 513-536.

Sampson, V., \& Walker, J. P. (2012). Argument-driven inquiry as a way to help undergraduate students write to learn by learning to write in chemistry. International Journal of Science Education, 34(10), 1443-1485.

Sandoval, W. A., \& Millwood, K. A. (2005). The quality of students' use of evidence in written scientific explanations. Cognition and Instruction, 23(1), 23-55.

Shipstone, D. (1988). Pupils' understanding of simple electrical circuits. Physics Education, 23, 92-96.

Songer, N. B., \& Gotwals, A. W. (2012). Guiding explanation construction by children at the entry points of learning progressions. Journal of Research in Science Teaching, 49(2), 141-165.

Toulmin, S. (1958). The uses of argument. Cambridge, England: Cambridge University Press. 

to copy, distribute, transmit or adapt the article content, providing a proper, prominent and unambiguous attribution to the authors in a manner that makes clear that the materials are being reused under permission of a Creative Commons License. Views, opinions and conclusions expressed in this research article are views, opinions and conclusions of the author(s). Open Access Publishing Group and European Journal of Education Studies shall not be responsible or answerable for any loss, damage or liability caused in relation to/arising out of conflicts of interest, copyright violations and inappropriate or inaccurate use of any kind content related or integrated into the research work. All the published works are meeting the Open Access Publishing requirements and can be freely accessed, shared, modified, distributed and used in educational, commercial and non-commercial purposes under a Creative Commons Attribution 4.0 International License (CC BY 4.0). 